\title{
Editorial - global inequality and development after 1945
}

In 2002, the former chief economist of the World Bank, François Bourguignon, and the French development expert Christian Morrisson published an article entitled 'Inequality among world citizens: $1820-1992{ }^{1}{ }^{1}$ Even though the authors used mainly historical data from the past two centuries, the article - published in the American Economic Review was primarily directed at an economic audience. For most members of the profession, the findings of this enquiry were indeed surprising and challenged conventional wisdom. Bourguignon and Morrisson argued that the disparity in the worldwide distribution of income and wealth has worsened nearly continuously during the past two centuries, except for the crisis-torn 1930s and 1940s. However, the structure of inequality has changed over time. Whereas, during the nineteenth and early twentieth centuries, inequality was mainly due to differences within countries, after 1945 it was due to differences between countries. Consequently, in a long-term perspective, the problem of inequality has shifted from a national to a global level.

These findings gave rise to controversy. While many development experts saw their longstanding claim reaffirmed that fostering economic equality constituted the single most important challenge to contemporary global governance, other economists questioned the methodology of Bourguignon and Morrisson. By integrating microeconomic surveys of 138 countries between 1970 and 2000 and population-weighted national accounts into a World Distribution Index (WDI), Xavier Sala-i-Martin presented a completely different picture. $^{2}$ According to the WDI, global poverty rates declined significantly over the last three decades. In particular, the internal dynamics of the two largest national populations of the world - India and China - had produced wealth that remained unaccounted for in many other studies. Sala-i-Martin concluded: 'The world might just be in a better shape than many of our leaders believe! ${ }^{3}$

1 American Economic Review, 92, 4, 2002, pp. 727-44.

2 Xavier Sala-i-Martin, "The disturbing "rise” of world income inequality', NBER Working Paper 8904, April 2002, http://www.nber.org/papers/w8904.pdf (consulted 8 December 2010); idem, 'The world distribution of income: falling poverty and ... convergence, period', Quarterly Journal of Economics, 121, 2, 2006, pp. 351-97.

3 Sala-i-Martin, 'World distribution', p. 393. For further discussions see Charles Jones, 'On the evolution of the world income distribution', Journal of Economic Perspectives, 11, 3, 1997, pp. 19-36; Paul T. Schultz, 'Inequality and the distribution of personal income in the world: how it is changing and why', Journal of Population Economics, 11, 3, 1998, pp. 307-44; Glenn Firebaugh, 'Empirics of world income inequality', American Journal of Sociology, 104, 1999, pp. 1597-1630; Arne Melchior, Kjetil Telle, and Henrik Wiig, Globalisation and inequality: world income distribution and living standards, 1960-1998, Oslo: Royal Norwegian Ministry of Foreign Affairs, 2000; Branko Milanovic, Worlds apart: measuring international and global inequality, Princeton, NJ: Princeton University Press, 2005; Angus Deaton, 'Measuring poverty in a growing world (or measuring growth in a poor world)', Review of Economics and Statistics, 87, 1, 2005, pp. 1-19. 
This controversy paradigmatically displays how strongly the present debate on global inequality is based on historical arguments. Moreover, it underlines that these controversies take place in a highly abstract mode of knowledge production that is, in itself, the result of the intellectual history of the twentieth century. With this special issue, we wish to open up new research trajectories dealing with the genesis of such abstract knowledge claims. At the same time, however, we place them in the context of a history of basic human needs such as food, shelter, and security. The discourse on global inequality that arose after the Second World War was not merely the result of scientific research and data production. It was, in fact, deeply intertwined with the political agendas of states, non-governmental organizations, and international agencies in this field. Instead of presenting new statistical evidence on the quantitative evolution of inequality, this special issue aims to reconstruct the political, economic, and scientific discourse on global inequality and development after 1945.

In this context, six observations seem important. First, even though the global dimensions of inequality are obvious, there are only a few empirical studies that analyse this problem in a long-term perspective. Social scientists and historians have shared a tradition of enquiry that explores social differentiation and class struggle mainly within national communities. For instance, the emergence of the 'welfare state' since the nineteenth century constitutes a prominent research paradigm that has shaped generations of scholars. Against this background, the global dimensions of inequality have been almost completely neglected. While there is an emerging strand of research on different growth experiences in the world, especially during the period of industrialization (the 'Great Divergence'), there are just a handful of historically informed studies on the problem of international income and wealth distribution. ${ }^{4}$ Until recently, this was a field almost entirely dominated by economists, who regarded the past as an accumulation of data that can be used to test econometric models. ${ }^{5}$

Secondly, historical long-term analyses have methodological shortcomings. Most studies are based on data provided by the growth accountants of the Organisation for Economic Co-operation and Development (OECD). ${ }^{6}$ This empirical basis is built on the national accounting concept and makes the comparison of the average per-capita income of different nation-states possible. However, the quality of such aggregates deteriorates with increasing distance from present-day industrialized countries. While European and North American experiences from the middle of the nineteenth century up to the present are more or less adequately represented in national accounts, the available estimates for Asian, Latin American,

4 See, for example, Jeffrey G. Williamson, 'Real wages, inequality, and globalization in Latin America before 1940', Revista de Historia Económica, 17, 1999, pp. 101-42; Kevin H. O’Rourke, 'Globalization and inequality: historical trends', NBER Working Paper 8339, 2001, http://www.nber.org/papers/ w8339.pdf (consulted 8 December 2010); Leandro Prados de la Escosura, 'Inequality and poverty in Latin America: a long-run exploration', in Timothy J. Hatton, Kevin H. O'Rourke, and Alan M. Taylor, eds., The New Comparative Economic History, Cambridge, MA: MIT Press, 2007, pp. 291-315; Luis Bértola, Cecilia Castelnovo, Javier Rodríguez, and Henry Willebald, 'Between the colonial heritage and the first globalization boom: on income inequality in the southern cone', Revista de Historia Económica, 28, 2, 2010, pp. 307-41.

5 See, for example, Philippe Aghion and Jeffrey G. Williamson, eds., Growth, inequality, and globalization, Cambridge: Cambridge University Press, 1998; Daron Acemoglu, Simon Johnson, and James Robinson, 'Reversal of fortune: geography and development in the making of the modern world income distribution', Quarterly Journal of Economics, 117, 4, 2002, pp. 1231-94.

6 Angus Maddison, The world economy: historical statistics, Paris: OECD, 2003; see also idem, The political economy of poverty, equity, and growth: Brazil and Mexico, Oxford: Oxford University Press, 1992. 
and African states are at times rather poor and become increasingly fictitious the further back one looks. Enquiry into biological standards of living have been used as an alternative to the national accounts approach but findings are still scarce and far between. ${ }^{7}$ Thus, historical research into the dynamics of global economic inequality cannot fully rest upon macro-statistical comparison but needs to embrace qualitative strategies of enquiry. Historical case studies must be set into a well-reasoned comparative framework.

However, despite these observations, methodological problems prevail, constituting a third fundamental issue in the literature. For instance, questions of poverty directly relate to social mobility or to the equity of individual opportunities with respect to gender and cultural difference. Currently, there is no generally accepted procedure in view that could allow for a coordination of comparative research. In contrast, contradictory concepts of culture are in use and understandings of poverty and wealth both lack clear definition. Not even within the relatively consistent approach that focuses solely on income and wealth distribution have standard definitions of inequality emerged. ${ }^{8}$ The methodological problems of a comparative global enquiry dwarf the considerable difficulties that have kept research on social inequality within single nation-states a lively field of academic work for so long. The problem has systematic philosophical dimensions, since any proposition for a universal analytical framework has to face the challenge of reducing the complexities of the human condition to one dominant approach. ${ }^{9}$

Fourthly, as Johannes Berger reminds us, ${ }^{10}$ research on inequality necessarily implies that a normative dimension must be applied as some kind of yardstick in order to measure differences. But norms change over time. Historians therefore need to reflect carefully on their implicit assumptions, while clearly explaining them. This is best done by making the history of norms themselves an object of historical study. It was only towards the middle of the twentieth century that concepts such as hunger, poverty, inequality, or development became core ideas to describe the global human collectivity. The creation of comparative knowledge about these problems and its generalized application to the human past are relatively recent forms of scientific practice, and the history of these epistemic techniques and of moral standards is difficult to separate from the history of global inequality.

Fifthly, social scientific and historical research on income and its distribution always was a predominantly political undertaking. No other topic has had such a profound impact on political struggles and social conflicts. Again, it is fairly difficult to reconstruct

7 Jörg Baten and Alexander Moradi, 'Inequality in Sub-Saharan Africa 1950-80: new estimates and new results', World Development, 33, 8, 2005, pp. 1233-65; Jörg Baten and Aravinda Meera Guntupalli, 'The development and inequality of heights in north, west and east India, 1915-44', Explorations in Economic History, 43, 4, 2006, pp. 578-608; Markus Baltzer and Jörg Baten, 'Heights, inequality, and trade in the Latin American periphery, 1950-2004', Economics and Human Biology, 6, 2, 2008, pp. 191-203.

8 Martin Ravallion, 'Competing concepts of inequality in the globalization debate', World Bank working paper no. 3243, 2004, http://www-wds.worldbank.org/servlet/WDSContentServer/WDSP/IB/2004/06/ 08/000009486_20040608155900/Rendered/PDF/wps3243inequality.pdf (consulted 8 December 2010).

9 Seyla Benhabib, 'Cultural complexity, moral independence, and the global dialogical community', in Martha C. Nussbaum and Jonathan Glover, eds., Women, culture, and development: a study of human capabilities, Oxford: Oxford University Press, 1995, pp. 235-55.

10 Johannes Berger, 'Inequality', in Austin Harrington et al., eds., Encyclopedia of Social Theory, London: Routledge, 2006, pp. 275-8; idem, 'Nimmt die Einkommensungleichheit weltweit zu? Methodische Feinheiten der Ungleichheitsforschung', Leviathan, 33, 4, 2005, pp. 464-81. 
these political conflicts on an international level. While, within the nation-state, new political instruments have emerged since the nineteenth century in order to mitigate developing inequalities (tax system, social welfare, etc.), there are few comparable institutions on a global scale. However, issues of poverty and social inequality provided the rationale behind the creation of many international organizations in the post-war era. Even though these organizations had only a limited impact, they offer a starting point for the historical analysis of international politics, global inequality, and the North-South conflict after 1945. Historical research on international bodies such as the International Labour Organization (ILO), the United Nations Conference on Tariffs and Trade (UNCTAD), or the OECD is still at an infant stage. It has so far largely been dominated by the experts in international policy advice themselves. ${ }^{11}$

Finally, historians largely agree that the long twentieth century was an epoch of unprecedented global interaction. The integration of the world economy, novel forms of mobility and communication, and new conflicts and crises have made world history move far beyond its alleged end. ${ }^{12}$ Research on global inequality must be connected to these processes of globalization. The question is not only whether 'globalization' as a process increased or decreased the gap between rich and poor. It is also a question of the ways in which the perceptions and realities of inequality worked as agents in intensifying global mobility and communication. We need to know how the problem of inequality on a large scale structured the emergence of the global realm of 'domestic' politics, however weak the action might have been that was undertaken in this respect. A final observation thus unveils the fundamental paradox that global inequality strongly contributed to the rise of new global connections and new forms of mobility. ${ }^{13}$

With this special issue we wish to stimulate historical reflection on a topic that has been judged by Charles S. Maier to be one of the prominent moral narratives of twentieth century's history: namely, the emergence of global inequality. ${ }^{14}$ The articles are far from resolving those fundamental contradictions that become evident if one takes the above six observations seriously. Instead, they invite the historian to proceed with a certain epistemic modesty that acknowledges the importance of the single case. They strongly emphasize the history of knowledge about inequality when they tackle the problem of historical inequality itself. And they design new approaches to the history of the international organization of the post-1945 world.

The collection has three contributions that track discourses on inequality more generally. Daniel Speich analyses the history of quantitative economic enquiry by taking a close look at the invention and global proliferation of national accounts. Alexander Nützenadel and Ruth Jachertz reconstruct the emerging global discourse on hunger; while Marc Frey pro-

11 Richard Jolly et al., UN Contributions to development thinking and practice, Bloomington, IN: Indiana University Press, 2004; Dudley Seers and Gerald M. Meier, eds., Pioneers in development, New York: Oxford University Press, 1984.

12 Francis Fukuyama, The end of history and the last man, New York and Toronto: Free Press and Maxwell Macmillan, 1992.

13 Michael Geyer and Charles Bright, 'World history in a global age', American Historical Review, 100, 4, 1995, pp. 1034-60.

14 Charles S. Maier, 'Consigning the twentieth century to history: alternative narratives for the modern era', American Historical Review, 105, 3, 2000, pp. 807-31. 
files the rise and decline of an anti-natalist paradigm that made population politics a global issue. Three other articles focus on single agents or geographic spaces. Rivarola and Appelqvist analyse the role of two main intellectuals of the global discourse on inequality and development - Gunnar Myrdal and Raúl Prebisch - who also played an important role in international agencies such as the UNCTAD and the EEC. Michele Alacevich scrutinizes the early development concepts of the World Bank. Corinna Unger follows American modernization approaches into the Indian field of development policy implementation. Finally, David Engerman discusses the potential of the arguments presented for further research into a global history of inequality.

Alexander Nützenadel and Daniel Speich 